The amount of the displacement in gelatine films shown by precise measurements of stellar photographs

This content has been downloaded from IOPscience. Please scroll down to see the full text. 1922 Trans. Opt. Soc. 2441

(http://iopscience.iop.org/1475-4878/24/1/306)

View the table of contents for this issue, or go to the journal homepage for more

Download details:

IP Address: 130.237.165.40

This content was downloaded on 31/08/2015 at 09:42

Please note that terms and conditions apply. 


\title{
THE AMOUNT OF THE DISPLACEMENT IN GELA- TINE FILMS SHOWN BY PRECISE MEASUREMENTS OF STELLAR PHOTOGRAPHS
}

\author{
BY C. DAVIDSON, F.R.A.S. \\ (Communicated by SIR F. DYson) \\ Read and discussed, I th Fanuary, 1923.
}

THE amount and the nature of the distortion to which a photographic film is subject is of great importance in astronomy where photography enters so largely into modern methods of precise observation. There are two general cases of distortion to consider, $(a)$ when the images are small in themselves and small in relation to the distances separating them, and $(b)$ when the images are large and no lower limit is placed on the separation. The second case has been very exhaustively dealt with by Dr Ross in the Research Laboratory of the Kodak Company. The first case is that of an ordinary astronomical photograph and is the subject of this note.

A stellar photograph consists of a large number of tiny discs scattered over an otherwise transparent plate and the purpose of the photograph is to determine the exact relative positions of these points. How far may the gelatine film be trusted not to have moved laterally on its support?

Some I6 years ago Prof. Schlesinger, when contemplating the application of photographic methods to the determination of stellar parallaxes, made a short study of the problem. Any displacement of the film is most likely to take place during the critical operations of developing, fixing, washing and drying. Schlesinger therefore took a phoiograph of a star field and after development, etc., measured it. The plate was then treated as if it had never been developed, that is, it was immersed for 5 mins. in a developer, ro mins. in a fixing bath and 60 mins. in running water. After drying in a vertical position it was again measured and from a discussion of the results he deduced a probable error of film distortion of $\pm .0006 \mathrm{~mm}$. On a similar plate which was plunged for 10 mins. into hot water at a temperature of $86^{\circ}$ the probable error of distortion came out at $\pm .0003 \mathrm{~mm}$. Contrary to expectation the hot water had not increased the distortion. After various other methods of ill treatment had been tried with much the same result he came to the general conclusion that with ordinary treatment film displacement was not likely to exceed $.00 \mathrm{rmm}$.

The trigonometrical determination of the distance of a star is accomplished by taking photographs of the region near the star at two epochs, the second epoch 
about 6 months after the first, when the earth will have moved through half its orbit and is consequently $300,000,000$ kilometres distant from the point at which the first photographs were taken. If the star is at a measurable distance it will appear to have moved slightly relatively to the stellar background, the parallactic movement being inversely proportional to its distance. On each plate the position of the image of the star whose parallax is to be determined together with those of some half dozen faint stars of the background are measured against a scale. The measured positions on the several plates are fitted together algebraically and the small outstanding difference of the parallax star between the two epochs is interpreted as its parallactic motion. When, from a series of photographs, the parallax has been determined and subtracted from the individual results each plate will show a residual error. This residual is made up of several errors of which the observing and measuring errors are probably the most important, and also photographic image error and film displacement. The mean of a large number of these residuals shows that the average probable error of the measured position on a single plate does not exceed $.0008 \mathrm{~mm}$. It follows then that the probable error of film displacement, which is only a part of the total error, will not exceed this figure, thus confirming Schlesinger's conclusion.

When the observation of stellar parallaxes was commenced at Greenwich, the telescope being of comparatively, short focus, even an error of $\cdot 00 \mathrm{I} \mathrm{mm}$. could not be safely neglected and the method of observation was that proposed by the late Prof. Kapteyn. Photographs at the two epochs were taken on a single plate which was stored away during the interval and developed after the second exposure. It was so arranged that the developed plate showed the two sets of images closely juxtaposed. It was only necessary to measure the distance between them and as this distance was very small both images might be expected to be equally affected by any film displacement, which would be eliminated in their differences.

The method was sound but after a prolonged trial has now been given up on account of climatic difficulties, and each photograph is now taken on a single plate. The Kapteyn pairs can however be compared as single photographs and so provide material from which the film error may be deduced. For if the total error of a plate is made up of

$$
\epsilon_{1}, \epsilon_{2} \text {, etc., } \epsilon_{f} \text {, where } \epsilon_{f} \text { is the film displacement }
$$

then the residual of one member of a Kapteyn pair is

$\begin{aligned} & \pm \epsilon_{1}+\epsilon_{f} \\ \text { and the other } & \pm \epsilon_{2}+\epsilon_{f}\end{aligned}$

$\epsilon_{f}$ being the same for both.

The sum gives

$\pm \sqrt{2 \epsilon^{2}+4 \epsilon_{f}^{2}}$

the difference

$\pm \sqrt{2 \epsilon^{2}}$

where $\epsilon$ is the probable error due to all causes except the film displacement, and $\epsilon_{f}$ that due to film displacement alone. 
Reference to the following table, which is only a small portion of the material used, will indicate the magnitude of error which may be expected.

\section{Residuals on "Kapteyn" plates}

\begin{tabular}{|c|c|c|c|}
\hline $\begin{array}{c}\text { Ist exposure. } \\
\pm \varepsilon_{1}+\epsilon_{j} \\
\mathrm{IO}^{-4} \mathrm{~mm}\end{array}$ & $\begin{array}{c}\text { 2nd exposure. } \\
\pm \varepsilon_{2}+\varepsilon_{f} \\
10^{-4} \mathrm{~mm}\end{array}$ & $\begin{array}{l}\text { Sum. } \\
\pm \sqrt{2 \epsilon^{2}+4 \epsilon^{2}} \\
10^{-4} \mathrm{~mm} .\end{array}$ & $\begin{array}{l}\text { Difference. } \\
\quad \pm \sqrt{2 \epsilon^{2}} \\
10^{-4} \mathrm{~mm} .\end{array}$ \\
\hline $\begin{array}{r}7 \\
+14\end{array}$ & $\begin{array}{l}+4 \\
+10\end{array}$ & $\begin{array}{r}3 \\
24\end{array}$ & $\begin{array}{r}11 \\
4\end{array}$ \\
\hline-16 & -7 & 23 & 9 \\
\hline-15 & -16 & $3 \mathrm{I}$ & I \\
\hline-5 & $+\mathrm{II}$ & 6 & 16 \\
\hline-13 & -7 & 20 & $\begin{array}{l}6 \\
8\end{array}$ \\
\hline $\begin{array}{l}+7 \\
+7\end{array}$ & $\begin{array}{l}-\mathrm{I} \\
+\quad 6\end{array}$ & $\begin{array}{l}6 \\
7\end{array}$ & $\begin{array}{l}8 \\
5\end{array}$ \\
\hline $\begin{array}{r}1 \\
+\quad 6\end{array}$ & +6 & 7 & 5 \\
\hline+7 & -6 & I & I 3 \\
\hline$-I$ & -5 & 6 & 4 \\
\hline+3 & +6 & 9 & 3 \\
\hline-12 & $-I$ & I3 & I I \\
\hline$+I_{4}$ & 0 & 14 & $r_{4}$ \\
\hline- II & -3 & 14 & 8 \\
\hline+8 & -9 & $\mathrm{I}$ & I7 \\
\hline$=3$ & $\begin{array}{l}+27 \\
-10\end{array}$ & $\begin{array}{l}24 \\
38\end{array}$ & $\begin{array}{c}30 \\
0\end{array}$ \\
\hline $\begin{array}{r}-19 \\
-\quad 7\end{array}$ & $\begin{array}{r}-19 \\
0\end{array}$ & $\begin{array}{r}38 \\
7\end{array}$ & 7 \\
\hline-9 & $+I I$ & 2 & 20 \\
\hline-2 & +22 & 20 & 24 \\
\hline-14 & -18 & 32 & 4 \\
\hline-8 & -4 & 4 & 12 \\
\hline$-2 I$ & $\begin{array}{r}\circ \\
-8\end{array}$ & 2 I & 21 \\
\hline+22 & +8 & 30 & 14 \\
\hline
\end{tabular}

From a discussion of the residuals of some 300 Kapteyn plates measured in this way it is found that

whence

$$
\begin{aligned}
\sqrt{2 \epsilon^{2}+4 \epsilon_{f}^{2}} & = \pm .00122 \mathrm{~mm}, \\
\sqrt{2 \epsilon^{2}} & = \pm .00106 \quad, \\
\epsilon_{f} & = \pm .00030 \quad,
\end{aligned}
$$

Although the method is somewhat insensitive it is considered that this result is not greatly in error.

Occasionally a measured position is found to have a residual error several times in excess of the probable error, $\pm .0008 \mathrm{~mm}$, given above. Sometimes the cause can be definitely located and in several cases it has been traced to local film distortion through uneven drying of the photograph. Another cause is the proximity of a bright star image giving rise to the well-known "Ross" effect.

Some years ago Mr Bellamy at Oxford Observatory had noted cases of distortion caused by bright star images on astrographic photographs and also published a note giving a collection of measures of double stars from photographs which showed that the photographic distances were generally smaller than those observed directly at the telescope.

Dr Ross, in 1918, published the results of his researches on the subject and showed that under certain conditions with tanning developers like pyro and caustic 
hydroquinone, stellar discs contract in drying, giving rise to a distortion in the immediate neighbourhood, and from a study of photomicrographs of wet and dry films was able to give the following explanation.

That particular physical property of gelatine which is most strongly affected by chemical action is hydration or ability to absorb water. When a photographic emulsion dries on a plate the natural tendency on dehydrating is to shrink equally in all directions but on account of its strong physical affinity for glass it is unable to do so in the plane parallel to the plate. As a result there is a residual stress in this direction. When an emulsion is stripped from its support it will swell in its own plane only 25 per cent. on complete hydration. It is clear that though its horizontal elasticity or ability to swell has not been entirely lost yet the physical structure of the gelatine has been profoundly modified by the stresses to which it has been subjected while drying on its glass support.

The phenomenon of contraction of photographic images and distortion in general can now be explained. On account of the smaller water content of the tanned developed image as compared with that of the gelatine surrounding it, the image dries more quickly. Stresses parallel to the plate at the edge of the image become unbalanced since the normally active counterbalancing stresses acting outward from the edge of the image have not yet developed owing to the still wet condition of the gelatine surrounding the image. There is therefore a movement inward of the outer ring of the image greatest at its extreme edge and diminishing gradually towards the centre. With the edge moving inward the gelatine in its immediate neighbourhood is dragged along by an amount which appears to be an exponential function of the distance from the edge. This accounts for the translatory motion of star images, large in the immediate vicinity of the edge and decreasing rapidly with increase of distance.

In the case of double stars the separate images are so close together that the intervening gelatine must be in nearly the same condition as to moisture content as the images themselves. The two images therefore act as a unit, contraction taking place towards the centre of gravity with a consequent diminution of the distance separating them.

A photographic plate dried unevenly is subject to unbalanced stresses of a similar nature and single star discs may be displaced in position in consequence. In the cases of large residual error referred to above there was distinct evidence that, in draining, isolated drops of water had remained on the film very close to the star images so that this part of the film was still wet after the remainder of the film was dry, thus producing an unbalanced stress and consequent distortion.

\section{DISCUSSION}

Sir F. Dyson: Owing to the great care taken in connection with the work to which Mr Davidson has referred we are able to get as good results with our $20 \mathrm{ft}$. telescope as are obtained elsewhere with larger telescopes. The amount of distortion in celluloid films is probably greater than in the case of plates.

Commander T. Y. Baker: At the Admiralty Research Laboratory we have recently had occasion to take this question into consideration in connection with a problem in which we were obliged to use films and not plates. We have found that there is nothing like the same freedom from distortion in films as Mr Davidson has found in the case of plates. Films exhibit a general contraction of the order of $\mathrm{I}$ per cent. and in addition local distortion of an amount greater than we could allow for. 
$\mathrm{Mr}$ R. W. Cheshire: The method we employed in connection with this work was to obtain a contact print of a $10 \mathrm{~cm}$. glass scale. This was developed, fixed, washed, and dried and then placed in contact with the scale, being slightly displaced to one side. By means of a travelling microscope we could then measure the average contraction of each $2 \mathrm{~cm}$. interval, and also get an idea of the amount of local distortion. If measured in a wet condition the film exhibits an increase in length of about $\frac{1}{2}$ per cent. On drying, it shows an immediate decrease of about $\frac{1}{5}$ per cent. and eventually a decrease of about $\mathrm{I}$ per cent.; furthermore, diurnal variations in the overall length of a film amounting to $\frac{3}{4}$ per cent. have been observed. The local distortions amount to 5 or $6 \mu$ as a maximum, but these can be eliminated by subsequent washing. If two pieces of film are taken from the same spool, the images formed on them may differ by as much as $\frac{1}{11}$ per cent. in overall length. The kind of accuracy realisable with films does not approach that obtained with plates.

Has Mr Davidson ever noticed the Ross contraction in images of the sun or moon?

Mr Davidson: I have not measured anything like this in the case of sun or moon images. Although the photographic diameters of the sun and moon are theoretically affected by the Ross distortion it is probable that the common optical aberrations of the telescope, atmospheric conditions, and irradiation would together effectually mask it. The same applies to star discs taken for photometric measurements.

Is the contraction of the celluloid film uniform in all directions?

Mr Cheshire: The measurements were made only in one direction.

Mr T. Smith: Can you give the thickness of the celluloid? Was the film coated with gelatine on one or both sides?

Mr Cheshire: I do not know what the thickness was. The film was the so-called non-curling variety and was coated on both sides.

Mr P. F. Everitt: On account of its physical properties celluloid seems to be quite an unreliable material for any work connected with accurate measurements.

Mr B. V. Storr: The celluloid used for the films mentioned by $\mathrm{Mr}$ Cheshire is generally 5 mils. thick, and is coated on one side with the emulsion, and on the other side with plain gelatine solution. In some recent measurements of the effect of various photographic solutions on celluloid film I found an expansion of the film when wet which varied in amount with the direction of measurement, while the recovery on drying was also irregular. The irregularity is probably due to unequal strains being set up in the celluloid film in its manufacture.

There is I think one other possible source of error in the measurement of astronomical photographs in addition to those considered by Mr Davidson this evening, and one which, if I remember rightly, was not dealt with by Ross. The relationship between density and exposure in a photographic plate is such that, within certain limits, the sum of the effect of two very small exposures acting 
separately is less than the combined effect if acting simultaneously on the same part of the plate; if the images of two prints or lines approach one another within a certain minimum this effect will come into play on the fringe of each image and the mass centres of the two images will approach one another slightly. I do not think the actual amount of this effect has ever been calculated or observed.

Regular drying is of the utmost importance. Variations in the rate of drying make themselves evident as marks on the plate. No plate should be used for measurements to within less than $\frac{1}{2}$ inch of the edge.

Mr Davidson: Do you recommend alcohol drying?

Mr O. F. Block: It is invariably best to use alcohol drying; 80 per cent. spirit is the most suitable strength to employ.

Mr F. Twyman: I am rather dismayed at the large amount of distortion possible and would like to know whether the Ross effect is taken into account in measurements of spectrum plates. I have not observed the effect in spectrographic work, but obviously, even if present only in a slight degree, it would be of great importance in the measurement for standards of spectra which contain numerous lines close together. Is the effect present when hydroquinone is used as a developer?

Sir F. Dyson: I do not know whether the effect is generally allowed for, but in conversation with Prof. Fowler I have gathered that he is aware of the effect.

Mr Davidson: In the Astrophysical fournal, vol. 52, p. 98, Ross states that the contraction results from the use of tanning developers such as pyro, pyro-metol, and caustic hydroquinone, but that hydroquinone, metol-hydroquinone, and chlorhydroquinone seem to give images free from this contraction effect.

Dr J. S. Anderson: Was the Ross effect taken into account in the famous measurements which substantiated Einstein's prediction?

Mr Davidson: The point has been carefully considered. On account of the diffuseness and small density of the corona and the relatively large distances of the stars it seems unlikely that their positions can be affected. In any event the Ross effect is in the opposite direction to the Einstein displacement.

* Mr J. Guild: The last slide which Mr Davidson showed reminds me of some experiments which I carried out some years ago in connection with the probable effect on spectrum lines. I had photographs taken of a suitably prepared diagram and after being dried they all exhibited marked troughs on the dark portions. This seems to be in contradiction to the results shown in the slide, for there, in the case of the dried negative, the dark portions were if anything slightly raised.

Mr Storr: The dark portions will naturally be raised for they contain bromide in addition to the gelatine which is common to the rest of the film.

Mr Guild (communicated later): I have re-examined the photographs to which I referred at the meeting and confirmed my recollection that the dark portions of the negatives are depressed below the level of the surrounding gelatine. 